\title{
Effectiveness and safety of exercise training and rehabilitation in chronic thromboembolic pulmonary hypertension: a systematic review and meta-analysis
}

\author{
Qin-Yan An ${ }^{1}$, Lan Wang ${ }^{2}$, Ping Yuan², Qin-Hua Zhao ${ }^{2}$, Su-Gang Gong ${ }^{2}$, Rui Zhang ${ }^{2}$, Jing He ${ }^{2}$, Ci-Jun Luo ${ }^{2}$, \\ Hong-Ling Qiu ${ }^{2}$, Hui-Ting Li ${ }^{1}$, Jin-Ming Liu ${ }^{2}$, Jing-Jing Wang ${ }^{3}$, Kuan Cheng ${ }^{4}$, Rong Jiang ${ }^{2}$ \\ ${ }^{1}$ Department of Respiratory, Sijing Hospital of Songiiang District, Shanghai, China; ${ }^{2}$ Department of Cardio-Pulmonary Circulation, Shanghai \\ Pulmonary Hospital, Tongji University School of Medicine, Shanghai, China; ${ }^{3}$ Department of Emergency, Shanghai Pulmonary Hospital, Tongji \\ University, Shanghai, China; ${ }^{4}$ Department of Cardiology, Zhongshan Hospital, Fudan University, Shanghai Institute of Cardiovascular Diseases, \\ Shanghai, China \\ Contributions: (I) Conception and design: QY An, K Cheng, R Jiang; (II) Administrative support: L Wang, JM Liu; (III) Provision of study materials \\ or patients: QH Zhao, SG Gong, P Yuan, R Zhang; (IV) Collection and assembly of data: QY An, JJ Wang, K Cheng, R Jiang; (V) Data analysis and \\ interpretation: QY An, HT Li, HL Qiu, J He, CJ Luo; (VI) Manuscript writing: All authors; (VII) Final approval of manuscript: All authors. \\ Correspondence to: Rong Jiang, MD. Department of Cardio-Pulmonary Circulation, Shanghai Pulmonary Hospital, Tongji University School of Medicine, \\ No. 507 Zhengmin Road, Yangpu District, Shanghai 200433, China. Email: listening39@163.com; Kuan Cheng, MD. Department of Cardiology, \\ Zhongshan Hospital, Fudan University, Shanghai Institute of Cardiovascular Diseases, Shanghai, China. Email: chengkuanck@aliyun.com.
}

Background: Patients with chronic thromboembolic pulmonary hypertension (CTEPH) still have impaired exercise training and quality of life (QoL) despite pulmonary arterial hypertension (PAH)-targeted drugs. Exercise training is considered to improve exercise capacity and QoL in patients with pulmonary hypertension $(\mathrm{PH})$, but this has not been fully studied in CTEPH patients. We conducted the meta-analysis and systematic review to evaluate the effectiveness and safety of exercise training in patients with CTEPH.

Methods: The relevant literature was retrieved for the meta-analysis using the PubMed, EMBASE, and Cochrane Library databases published before December 2020. The primary outcome was a change in six-minute walk distance (6MWD). We also assessed the effect of exercise training on peak oxygen uptake per kilogram (peak $\mathrm{VO}_{2} / \mathrm{kg}$ ), mean pulmonary artery pressure (mPAP) assessed by right heart catheterization (RHC), N-terminal pro-brain-type natriuretic peptide (NT-proBNP), and QoL.

Results: A total of 6 studies with 234 exercise training patients were included. In the pooled analysis, 6MWD significantly improved by $70.14 \mathrm{~m}$ (WMD: 58.33 to 81.95, $\left.\mathrm{I}^{2}=0\right)$ after 3-week exercise training. After 12 or 15-week exercise training, 6MWD and peak $\mathrm{VO}_{2} / \mathrm{kg}$ significantly improved (WMD: $106.22 \mathrm{~m}, 95 \%$ CI: 65.90 to $146.55, \mathrm{I}_{2}=87.4 \%, \mathrm{P}<0.0001 ; 1.84 \mathrm{~mL} / \mathrm{min} / \mathrm{kg}$, $95 \% \mathrm{CI}: 0.72$ to $2.96, \mathrm{P}=0.001$, respectively). Furthermore, the mPAP decreased by $12.17 \mathrm{mmHg}$ after 12-week exercise training (95\% CI: -14.53 to $-9.82, \mathrm{P}<0.001, \mathrm{I}^{2}=99 \%$ ). The subscales of QoL such as physical function, general health perception, and mental health improved in varying degrees. NT-proBNP did not improve significantly in the pooled analysis. In addition, exercise training was well tolerated without major adverse events occurred during training, and the dropout rate was low.

Discussion: Exercise training may improve exercise capacity, mPAP, and QoL, and was well tolerated among patients with CTEPH. However, more large-scale multicenter studies are needed to confirm the effectiveness and safety of exercise training in patients with CTEPH.

Keywords: Rehabilitation; exercise training; chronic thromboembolic pulmonary hypertension (CTEPH); exercise intolerance; cardiorespiratory fitness

Submitted Jun 08, 2021. Accepted for publication Jul 14, 2021.

doi: 10.21037/apm-21-1758

View this article at: https://dx.doi.org/10.21037/apm-21-1758 


\section{Introduction}

Chronic thromboembolic pulmonary hypertension (CTEPH) is a rare complication of pulmonary embolism characterized by unresolved emboli initiating remodelling of pulmonary arteries leading to increase in pulmonary vascular resistance (PVR) (1). According to the $6^{\text {th }}$ World Symposium on pulmonary hypertension $(\mathrm{PH})$ diagnosis and classification criteria (2), CTEPH is classified as WHO group 4. It results in a marked increase in right ventricular remodeling, limited exercise capacity, progressive increase in breathlessness, and eventual right heart failure and death $(3,4)$. The standard of care, pulmonary endarterectomy (PEA), is the most effective therapy for operable CTEPH and can result in near normalization of pulmonary hemodynamics $(5,6)$. Apart from PEA, balloon pulmonary angioplasty (BPA) and/or medical treatment are the recommended options for patients with CTEPH who are ineligible for surgery or who have persistent/recurrent CTEPH after surgery (7-9). Riociguat is the only medical therapy approved for use in patients with CTEPH $(10,11)$. Other pulmonary arterial hypertension (PAH)-targeted therapies [including endothelin receptor antagonists (ERAs), phosphodiesterase type 5 inhibitors (PDE5is), and prostacyclin analogs] are used off label in routine practice $(12,13)$.

Today, CTEPH management is becoming truly multimodal, and advances in PEA, BPA, and PAH-specific drug therapies have significantly improved the prognosis of patients $(14,15)$. However, most patients still suffer exercise intolerance, even after PEA or BPA (9,14-16). Advances in PAH-targeted drug therapies, PEA, and BPA have significantly improved prognosis, and other new treatment regimens have been explored to further improve exercise capacity, quality of life (QoL), and even outcomes (17).

According to the 2019 European Respiratory Society (ERS) statement on exercise training and rehabilitation (18), exercise training has been shown to improve exercise capacity reflected by six-minute walk distance (6MWD) or oxygen consumption at peak exercise (peak $\mathrm{VO}_{2}$ and peak $\mathrm{VO}_{2} / \mathrm{kg}$ ), muscular function, quality of life (QoL), right ventricular function and pulmonary haemodynamics in different etiologies of $\mathrm{PH}$ patients, including inoperable CTEPH patients (16) or those after BPA (19). Exercise training has also been shown to improve exercise capacity in CTEPH patients after PEA, independent of the PEA therapy (16,20-22). While most studies have focused on patients with $\mathrm{PH}$, including CTEPH, few studies have explored the effect of exercise training on CTEPH patients only.
Therefore, because the benefit of exercise training in CTEPH patients is as yet uncertain, we conducted a metaanalysis and systematic review to evaluate the efficacy and safety of exercise training for patients with CTEPH.

We present the following article in accordance with the PRISMA reporting checklist (available at https://dx.doi. org/10.21037/apm-21-1758) (23).

\section{Methods}

\section{Search strategy and study selection}

A systematic literature search was conducted in the PubMed, EMBASE, and Cochrane Collaboration databases from their inception to March 2020. We used the terms "exercise training", "chronic thromboembolic pulmonary hypertension", and "rehabilitation" to identify studies which evaluated the effects of exercise training on CTEPH. The search was limited to English language articles. Furthermore, we hand-searched the references of the retrieved articles to identify studies not captured by our primary search strategy. We also sent mail to the corresponding authors of articles for available data. This study has been registered at PROSPERO (No. CRD42021236225).

\section{Study selection}

The inclusion criteria were: (I) patients diagnosed as CTEPH, and (II) the patients underwent exercise rehabilitation. The diagnosis of CTEPH and their treatment processes were determined according to the guidelines of CTEPH $(15,24)$. The excluded criteria were conference abstracts, animal studies, reviews, or editorials. We included 13 studies that evaluated the effectiveness and safety of exercise training on CTEPH patients.

\section{Data extraction}

Two reviewers (R.J. and QY.A.) extracted data performed the literature search, data extraction, and methodological grading independently. The following information was recorded: author, year of publication, demographic and clinical characteristics, study nature, hemodynamics, and exercise intervention outcomes. Disagreements were resolved by consensus.

\section{Outcomes}

The primary outcome was a change in $6 \mathrm{MWD}$. The 
secondary outcomes included:

(I) Changes of peak $\mathrm{VO}_{2}$ or peak $\mathrm{VO}_{2} / \mathrm{kg}$ evaluated by cardiopulmonary exercise testing (CPET);

(II) Changes in mean pulmonary artery pressure (mPAP) by right heart catheterization (RHC);

(III) N-terminal pro-brain-type natriuretic peptide (NT-proBNP) changes;

(IV) QoL changes assessed by the SF-36 questionnaire.

\section{Methodological quality}

The National Institutes of Health (NIH) quality assessment tool was used for quality assessments of pre-post interventional studies (Table S1) (25). We used the Cochrane Collaboration's tool to assess the risk of bias of the randomized controlled trials (RCTs) (26). Since less than 10 studies were included in the meta-analysis, publication bias were not assessed.

\section{Data synthesis and statistical analysis}

We used random-effects or fixed-effects models to quantitatively synthesize the evidence and to calculate the summary estimates according to $\mathrm{I}^{2}$. Continuous data were analyzed by the weighted mean difference (WMD).

Some studies report continuous variables in the form of quartile intervals or $95 \%$ confidence intervals (CI) rather than standard deviations (SD), which need to be converted to SD. The cases were excluded if they could not be transformed into SDs. RevMan 5.4 and Stata version 15 software (Stata Corp., College Station, Texas) were used for statistical analyses.

\section{Results}

\section{Characteristics of the participants and study designs}

We retrieved 46 studies for further detailed analysis after 144 initial articles were identified by searches, and included 6 studies in our meta-analysis (Figure 1). There was 1 RCT (19) and 5 pre-post intervention studies (16,20-22,27) involving 234 patients treated between 2012 and 2020.

All studies used a supervised exercise training program combined with aerobic exercise (treadmill or bicycle ergometer) and resistance training. All studies were performed in hospital for the first few weeks, with the exercise intensity titrated at $50-70 \%$ of the peak exercise capacity, followed by home-based exercise training. The demographics and characteristics of the participants are presented in Table 1.

\section{Quality assessment}

The quality assessment of the pre-post interventional studies is detailed in Table S1. Fukui et al.'s study (19) was evaluated by the Cochrane bias risk assessment tool. The study had a low risk of bias in terms of random sequence generation, allocation concealment, blinding, and outcomes assessment, and a high risk of bias for incomplete outcome data and selective reporting.

\section{Six-minute walking distance}

The 6MWD was reported in 5 studies involving 150 patients $(16,19,21,22,27)$. In 2 interventional studies $(16,22)$ which evaluated the absolute value of the $6 \mathrm{MWD}$ after exercise training, the 6MWD significantly improved by $67.99 \mathrm{~m}$ (95\% CI: 32.74 to $103.25, \mathrm{P}=0.0002, \mathrm{I}^{2}=72 \%$ ) after 12 to 15 weeks of exercise training (Figure $2 A$ ). In 3 studies $(19,21,27)$ which evaluated the relative value of the $6 \mathrm{MWD}$, the $6 \mathrm{MWD}$ significantly improved by $70.14 \mathrm{~m}$ (WMD: 58.33 to $81.95, \mathrm{I}^{2}=0$ ) after 3 -week exercise training, and this was mirrored by similar changes after $12 / 15$ weeks of exercise training (WMD: $106.22 \mathrm{~m}, 95 \% \mathrm{CI}: 65.90$ to $146.55, \mathrm{I}^{2}=87.4 \%$ ). Pooled analysis showed that exercise training significantly improved 6MWD results (WMD: $88.16 \mathrm{~m}, 95 \% \mathrm{CI}: 66.19$ to $\left.110.13, \mathrm{I}^{2}=82.3 \%, \mathrm{P}<0.0001\right)$ (Figure 2B).

\section{Oxygen consumption at peak exercise}

The peak $\mathrm{VO}_{2} / \mathrm{kg}$ was reported in 2 studies involving 52 patients $(16,19)$. There was a significant increase in peak $\mathrm{VO}_{2} / \mathrm{kg}$ after $12 / 15$ weeks of exercise training, with no heterogeneity $(1.84 \mathrm{~mL} / \mathrm{min} / \mathrm{kg}, 95 \% \mathrm{CI}: 0.72$ to 2.96 , $\mathrm{P}=0.001$ ) (Figure 3).

\section{Mean pulmonary arterial pressure}

The mPAP was reported in 2 studies involving 101 patients (20). Pooled analysis showed that mPAP decreased after 12-week exercise training (WMD: $-12.17 \mathrm{mmHg}$, 95\% CI: -14.53 to $-9.82, \mathrm{P}<0.001, \mathrm{I}^{2}=99 \%$ ) (Figure 4 ).

\section{N-terminal pro-brain-type natriuretic peptide}

Figure 5 shows the logarithmic scale changes in NT- 


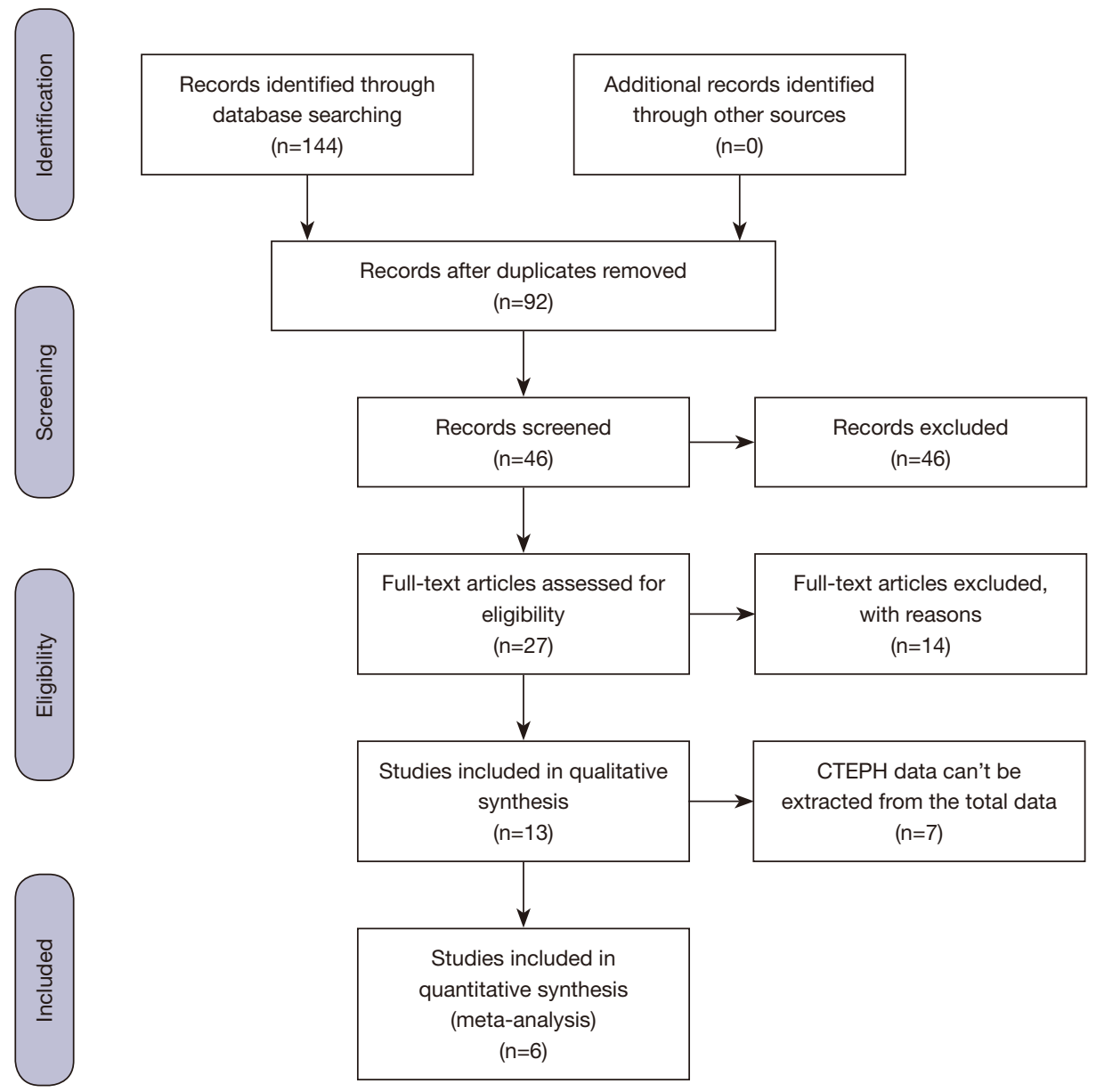

Figure 1 Flow diagram of the literature retrieval and inclusion process. CTEPH, chronic thromboembolic pulmonary hypertension.

proBNP plasma levels. In 2 studies (16,21), NT-proBNP levels decreased by $-0.28 \mathrm{ng} / \mathrm{L}$ (95\% CI: -2.43 to 1.87 ) after 3 weeks, but increased by $0.44 \mathrm{ng} / \mathrm{L}$ (95\% CI: -0.12 to 1.01 ) after $12 / 15$ weeks of exercise training in 3 studies $(16,19,22)$, without statistical significance.

\section{QoL}

QoL is substantially reduced in patients with CTEPH compared with the healthy population. QoL measures have been shown to correlate with clinical outcomes typically measured in CTEPH (28). Physical burden of the disease, unclear prognosis, high cost of treatment, unemployment and financial uncertainty, social relationships and psychological disorders have also been shown to significantly impact QoL in patients with CTEPH $(28,29)$. In 2 studies $(16,19)$, the subscales for physical function
(WMD: 9.97 points, 95\% CI: 8.89 to $11.04, \mathrm{P}<0.00001$, $\mathrm{I}^{2}=0$ ), general health perception (WMD: 9.88 points, $95 \%$ CI: 8.71 to $11.05, \mathrm{P}<0.00001, \mathrm{I}^{2}=51 \%$ ), and mental health (WMD: 9.91 points, $95 \%$ CI: 8.80 to $11.02, \mathrm{P}<0.00001$, $\left.\mathrm{I}^{2}=59 \%\right)$ improved after 15 -week exercise training rehabilitation (Table 2). However, role-physical, bodily pain, vitality, and role-emotional did not improve significantly.

\section{Muscle strength}

With regard to the muscle power, the quadriceps force increased by $3.4 \pm 3.8$ kilogram force after 12 -week exercise training in Takeshi Inagaki's study $(22)(\mathrm{P}<0.05)$. In Shigefumi Fukui's study (19), quadriceps force, but not forearm, significantly increased after 12-week exercise training in the cardiac rehabilitation group $(26.4 \pm 8.1 \mathrm{vs}$. $29.1 \pm 8.1 \mathrm{~kg}, \mathrm{P}<0.01)$. 


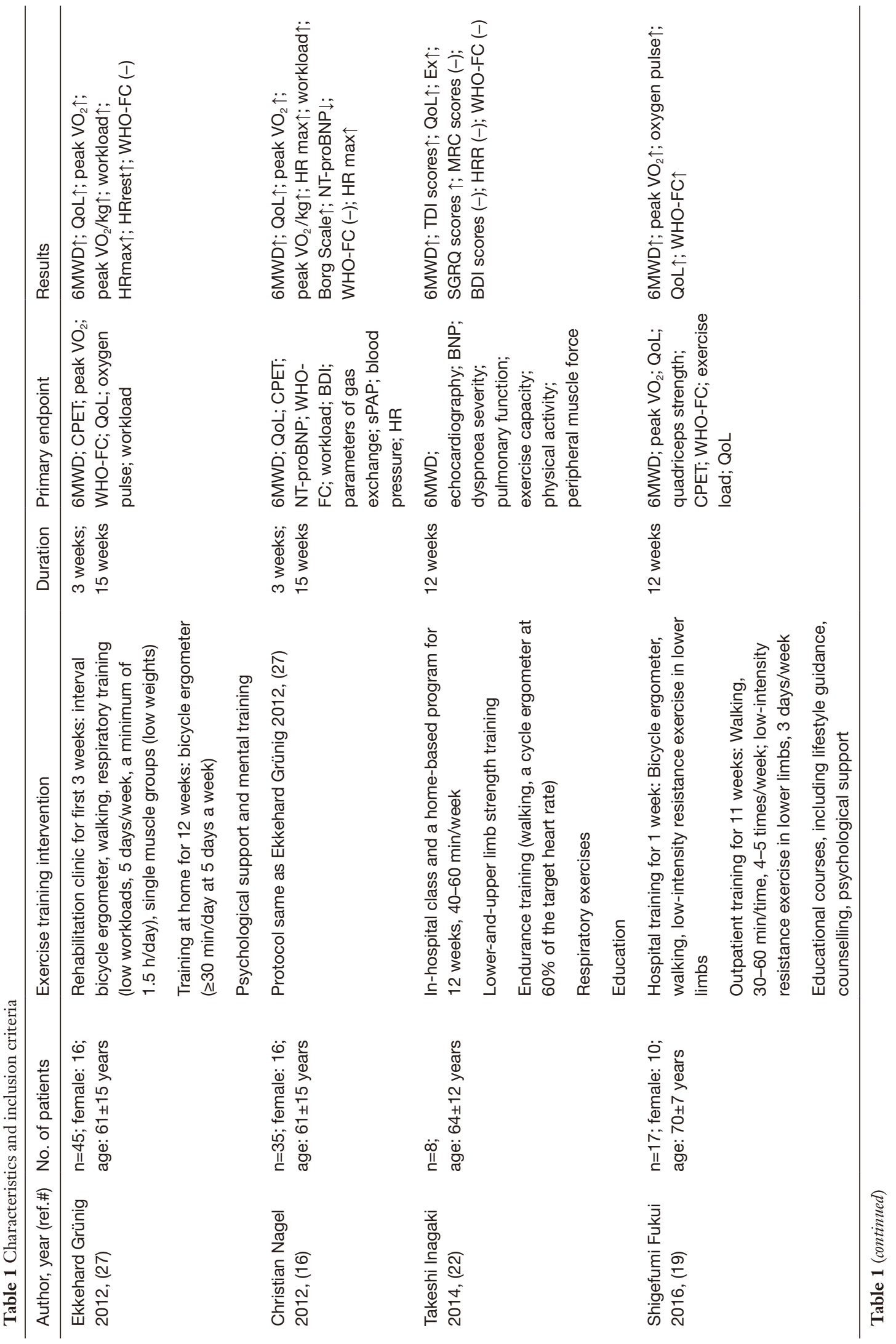




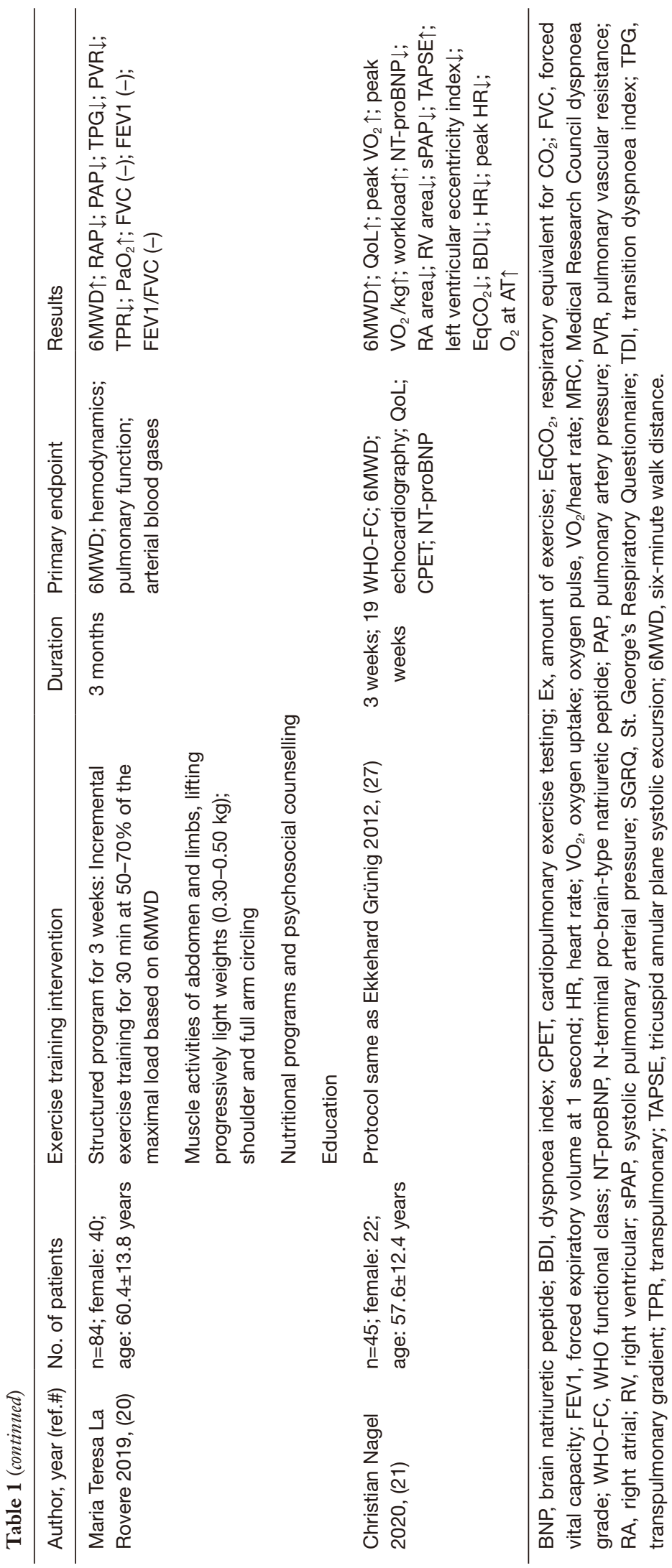




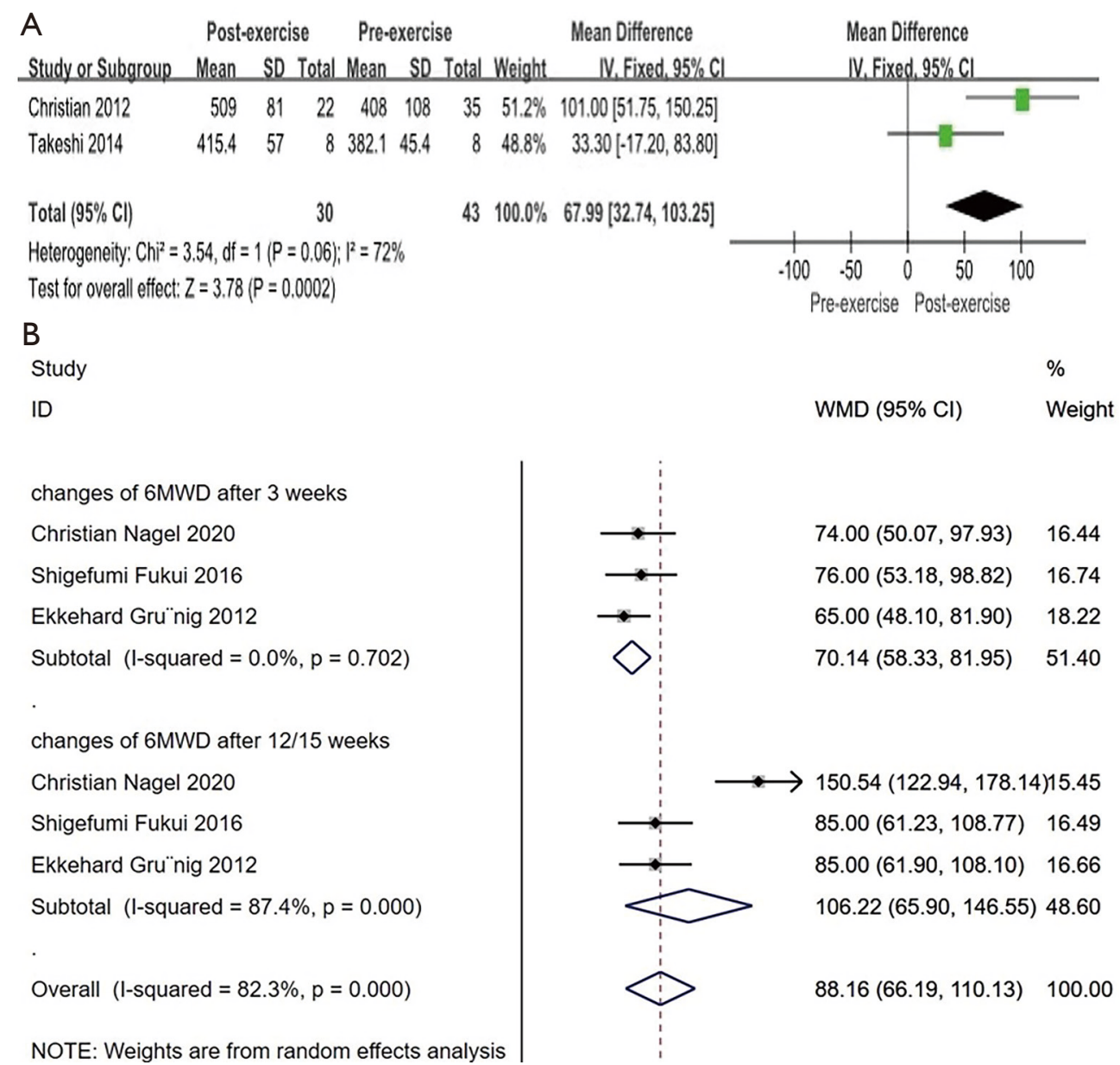

Figure 2 Forest plots for $6 \mathrm{MWD}$ after exercise training. (A) The absolute change of the $6 \mathrm{MWD}$; (B) the absolute change of the $6 \mathrm{MWD}$. $6 \mathrm{MWD}$, six-minute walking distance; CI, confidence interval; SD, standard deviation.

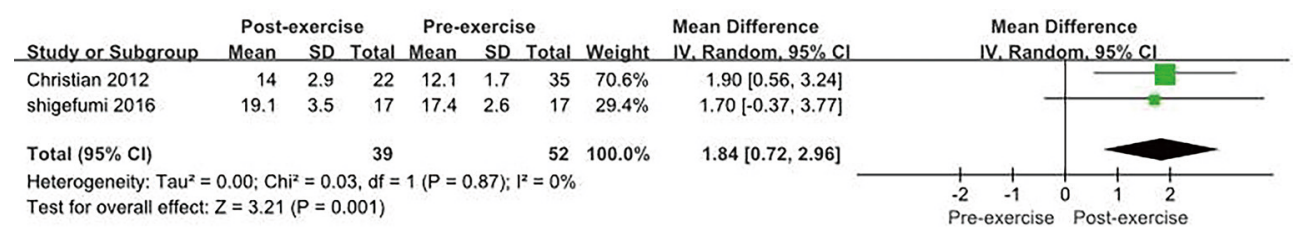

Figure 3 Forest plots for peak $\mathrm{VO}_{2} / \mathrm{kg}$. Peak $\mathrm{VO}_{2} / \mathrm{kg}$, peak oxygen consumption per kilogram; CI, confidence interval; SD, standard deviation; IV, inverse variance.

\section{Safety of exercise training}

In this study, exercise training was well tolerated, and the dropout rate was $3.8 \%$. About $3.5-5.6 \%$ of the patients who underwent training experienced syncope or palpitations. Furthermore, no major adverse events, such as symptom progression, right heart failure, or death, occurred during exercise training (Table 3).

\section{Discussion}

The results of meta-analysis suggest that patients with CTEPH can gain significant improved exercise capacity, cardiorespiratory fitness, and QoL after exercise training. 


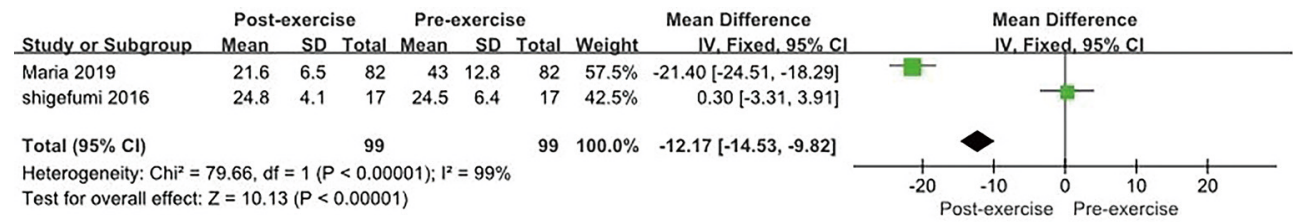

Figure 4 Forest plots for mPAP measured by right heart catheterization. mPAP, mean pulmonary arterial pressure; CI, confidence interval; $\mathrm{SD}$, standard deviation; IV, inverse variance.

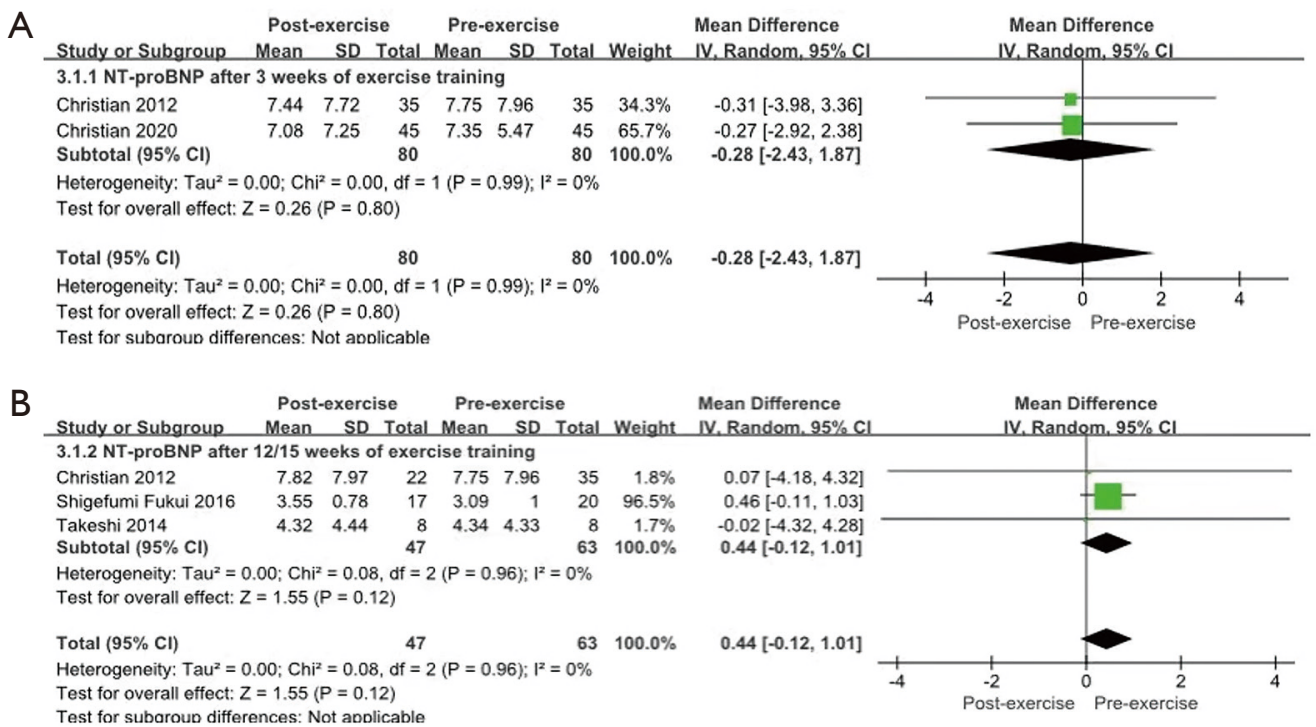

Figure 5 Forest plots for NT-proBNP. (A) NT-proBNP after 3 weeks; (B) NT-proBNP after 12 to 15 weeks. NT-proBNP, N-terminal probrain-type natriuretic peptide; CI, confidence interval; IV, inverse variance; SD, standard deviation.

Furthermore, exercise training was well tolerated with a low dropout rate.

Our study has important clinical implications. Because of the fear that exercise would worsen cardiac function, exercise rehabilitation was once discouraged in $\mathrm{PAH}$ patients. Recently, supervised exercise training rehabilitation has been recommended for $\mathrm{PH}$ patients with evidence of exercise rehabilitation (Class I, A) (30). The 2019 ERS exercise training and rehabilitation statement acknowledges the strong evidence of the benefits of exercise training in $\mathrm{PH}$ (18). Exercise training has shown beneficial effects as an add-on to PAH-specific drug therapies among patients with CTEPH (16).

\section{Effect of exercise training on exercise capacity and QoL}

6MWD, as the primary endpoint, has been demonstrated to be significantly increased in many studies (12,31-33). In this meta-analysis, exercise tolerance, measured by the 6MWD and peak $\mathrm{VO}_{2}$, significantly improved after exercise training.

From the summarized ERS statement on the QoL in many studies (18), bodily pain and general health perception generally have no significant differences. Our study indicated that physical functioning, general health perception, and mental health significantly improved in patients with CTEPH. Exercise training combined with PAH-specific drug therapies has shown beneficial effects among CTEPH patients (16). Current guidelines recommend $\mathrm{PEA}$ as the preferred treatment for patients with operable CTEPH (12,32). Additionally, BPA is an alternative therapy choice for inoperable patients $(34,35)$. A systematic review confirmed that BPA or PEA can improve exercise capacity (36).

After exercise training, patients with CTEPH after PEA had improved exercise tolerance for up to 3 months (20-22). 
Table 2 Changes in the quality of life of patients with CTEPH after exercise training

\begin{tabular}{|c|c|c|}
\hline Variable & WMD $(95 \% \mathrm{Cl})$ & $P$ value \\
\hline \multicolumn{3}{|l|}{ Physical functioning } \\
\hline Shigefumi Fukui 2016 (19) & $9.97(8.89,11.04)$ & $<0.00001$ \\
\hline \multicolumn{3}{|l|}{ Ekkehard Grünig 2012 (27) } \\
\hline \multicolumn{3}{|l|}{ Role-physical } \\
\hline Shigefumi Fukui 2016 (19) & $0.03(-1.50,1.56)$ & 0.97 \\
\hline \multicolumn{3}{|l|}{ Ekkehard Grünig 2012 (27) } \\
\hline \multicolumn{3}{|l|}{ Bodily pain } \\
\hline Shigefumi Fukui 2016 (19) & $0.01(-0.96,0.97)$ & 0.99 \\
\hline \multicolumn{3}{|l|}{ Ekkehard Grünig 2012 (27) } \\
\hline \multicolumn{3}{|l|}{ General health perception } \\
\hline Shigefumi Fukui 2016 (19) & $9.88(8.71,11.05)$ & $<0.00001$ \\
\hline \multicolumn{3}{|l|}{ Ekkehard Grünig 2012 (27) } \\
\hline \multicolumn{3}{|l|}{ Vitality } \\
\hline Shigefumi Fukui 2016 (19) & $0.07(-1.04,1.17)$ & 0.91 \\
\hline \multicolumn{3}{|l|}{ Ekkehard Grünig 2012 (27) } \\
\hline \multicolumn{3}{|l|}{ Role-emotional } \\
\hline Shigefumi Fukui 2016 (19) & $0.01(-0.93,0.95)$ & 0.98 \\
\hline \multicolumn{3}{|l|}{ Ekkehard Grünig 2012 (27) } \\
\hline \multicolumn{3}{|l|}{ Mental health } \\
\hline Shigefumi Fukui 2016 (19) & $9.91(8.80,11.02)$ & $<0.00001$ \\
\hline Ekkehard Grünig 2012 (27) & & \\
\hline
\end{tabular}

CTEPH, chronic thromboembolic pulmonary hypertension.

We included patients with PEA, BPA, or inoperable CTEPH. Although our meta-analysis showed that exercise training improved exercise capacity, we could not perform a subgroup analysis due to the limited number of included studies.

In previous studies, exercise training has been reported to improve exercise capacity and different aspects of QoL among different WHO groups of $\mathrm{PH}$ patients (12,16,18,31,37-39). In this study, we focused on the effect of exercise training on CTEPH patients. By pooled analysis, exercise training improved QoL to different degrees in patients with CTEPH.

\section{Effect of exercise training on bemodynamics and cardiac function}

The focus of most exercise training studies in the field of
$\mathrm{PH}$ are the changes in exercise capacity. Only 1 RCT study aimed to evaluate the changes of invasive hemodynamics during rest and exercise as secondary endpoints (33). Altogether, the study revealed a significant improved cardiac index, mPAP and PVR at rest among PAH or inoperable CTEPH patients after exercise training rehabilitation. So far, few exercise training studies have focused on the hemodynamics of CTEPH patients. Recently, a systematic review and meta-analysis evaluated the effectiveness and safety of exercise training in CTEPH after PEA (40). PEA surgery can improve hemodynamics (mPAP, transpulmonary resistance, cardiac output, cardiac index, PVR, systematic vascular resistance and pulmonary capillary wedge pressure) and right ventricular ejection fraction (RVEF) immediately. Three months of exercise training after PEA increased the RVEF by $3.53 \%$ (95\% CI: $6.31-11.94, \mathrm{P}<0.00001, \mathrm{I}^{2}=0$ ) independently of PEA surgery. However, 3 -month exercise training did not influence the hemodynamic parameters mentioned above.

In our study, the mPAP measured by RHC significantly decreased after 12-week exercise training. It is inferred that exercise training may improve pulmonary circulation, but more multicenter studies are needed to confirm this among patients with CTEPH.

This study also found that exercise training did not improve the logarithmic scale of NT-proBNP plasma levels. In the future, we need more studies to confirm the efficacy of exercise training on biomarkers.

\section{Muscle strength}

In this systematic review, only two studies evaluated the effects of exercise on muscle strength. Most current literature and evidence focus on the evaluation of exercise capacity, QoL, hemodynamics and echocardiography. Limited clinical trials of PAH focused on the effects of exercise training on skeletal and respiratory muscle function. Leg fatigue and dyspnoea during exercise are the main indications of skeletal muscle dysfunction in PAH patients (41). The underlying cause of peripheral muscle weakness is not completely clear, but may involve atrophy, capillary rarefaction, fibre type switch or sarcomeric dysfunction (42). Quadriceps muscle training has been shown to be effective in improving quadriceps muscle strength and endurance capacity in $\mathrm{PAH}$ patients (43). Inspiratory muscle strength largely depends on diaphragm muscle function, which can be explained by a reduction in force generating capacity of the diaphragm muscle fibres. Respiratory muscle dysfunction is common and 
Table 3 Exercise training-related adverse events

\begin{tabular}{lcl}
\hline Study & Number & Adverse events \\
\hline Christian Nagel 2012, (16) & 35 & Syncope in 1 patient; herpes zoster infection in 1 patient \\
Shigefumi Fukui 2016, (19) & 17 & None \\
Maria Teresa La Rovere 2019, (20) & 84 & None \\
Ekkehard Grünig 2012, (27) & 45 & Syncope in 1 patient; episodes of supraventricular tachycardia in 2 patients \\
\hline
\end{tabular}

may contribute to exercise limitation. Recently, a pilot RCT revealed inspiratory muscle training improved inspiratory muscle strength and functional exercise capacity in $\mathrm{PAH}$ and CTEPH (44). In future, larger multicentre studies should focus on the integrating programming of low-intensity endurance, strength, and breathing training programs in various forms of $\mathrm{PH}$, including CTEPH.

\section{Safety of exercise training}

In our systematic review, about $3.5-5.6 \%$ of the CTEPH patients experienced syncope or palpitations during exercise training. No major adverse events occurred among participants. However, consistent with the safety and efficacy of exercise training in various forms of $\mathrm{PH}$, exercise training was an effective but not a completely harmless addon therapy, and should be closely monitored $(18,27)$.

\section{Limitations}

First, there are limited studies which have evaluated the efficacy and safety of exercise training in patients with CTEPH. The sample size of the included studies was small, and most studies were not RCTs. Although several RCTs have evaluated the efficacy of exercise training in patients with PAH and CTEPH, data associated with CTEPH were not available. Second, most included studies were short-term studies, and did not evaluate prognosis endpoints. Therefore, we were unable to assess the continuous impact of exercise training on these clinical endpoints. Third, most studies were single-center studies, and future multicenter RCTs are needed to better characterize the long-term benefits in CTEPH patients in the real world. Finally, selection bias cannot be completely excluded for all meta-analyses.

\section{Conclusions}

The findings of the present meta-analysis suggest that exercise training may improve exercise capacity, including $6 \mathrm{MWD}$ and peak $\mathrm{VO}_{2} / \mathrm{kg}$. Exercise training also improves mPAP and QoL. However, more large-scale multicenter studies are needed to confirm the effectiveness and safety of exercise training in patients with CTEPH.

\section{Acknowledgments}

Funding: The work was funded by Shanghai Songiiang District Science and Technology Project (19 SJKJGG152), the Program of National Natural Science Foundation of China (81700045, 81870042, 82000059), and Program of Shanghai Pulmonary Hospital (FKLY20005).

\section{Footnote}

Reporting Checklist: The authors have completed the PRISMA reporting checklist. Available at https://dx.doi. org/10.21037/apm-21-1758

Conflicts of Interest: All authors have completed the ICMJE uniform disclosure form (available at https://dx.doi. org/10.21037/apm-21-1758). The authors have no conflicts of interest to declare.

Ethical Statement: The authors are accountable for all aspects of the work in ensuring that questions related to the accuracy or integrity of any part of the work are appropriately investigated and resolved. This study has been registered at PROSPERO (No. CRD42021236225).

Open Access Statement: This is an Open Access article distributed in accordance with the Creative Commons Attribution-NonCommercial-NoDerivs 4.0 International License (CC BY-NC-ND 4.0), which permits the noncommercial replication and distribution of the article with the strict proviso that no changes or edits are made and the original work is properly cited (including links to both the 
formal publication through the relevant DOI and the license). See: https://creativecommons.org/licenses/by-nc-nd/4.0/.

\section{References}

1 Memon HA, Lin CH, Guha A. Chronic

Thromboembolic Pulmonary Hypertension: Pearls and Pitfalls of Diagnosis. Methodist Debakey Cardiovasc J 2016;12:199-204.

2. Simonneau G, Montani D, Celermajer DS, et al. Haemodynamic definitions and updated clinical classification of pulmonary hypertension. Eur Respir J 2019;53:1801913.

3. Mourani PM, Sontag MK, Younoszai A, et al. Clinical utility of echocardiography for the diagnosis and management of pulmonary vascular disease in young children with chronic lung disease. Pediatrics 2008;121:317-25.

4. Seeger W, Adir Y, Barbera JA, et al. Pulmonary hypertension in chronic lung diseases. J Am Coll Cardiol 2013;62:D109-16.

5. Madani MM. Surgical Treatment of Chronic Thromboembolic Pulmonary Hypertension: Pulmonary Thromboendarterectomy. Methodist Debakey Cardiovasc J 2016;12:213-8.

6. Kim NH, Delcroix M, Jais X, et al. Chronic thromboembolic pulmonary hypertension. Eur Respir J 2019;53:1801915.

7. Brenot $\mathrm{P}$, Jais $\mathrm{X}$, Taniguchi $\mathrm{Y}$, et al. French experience of balloon pulmonary angioplasty for chronic thromboembolic pulmonary hypertension. Eur Respir J 2019;53:1802095.

8. Sugimura K, Fukumoto Y, Satoh K, et al. Percutaneous transluminal pulmonary angioplasty markedly improves pulmonary hemodynamics and long-term prognosis in patients with chronic thromboembolic pulmonary hypertension. Circ J 2012;76:485-8.

9. Mahmud E, Madani MM, Kim NH, et al. Chronic Thromboembolic Pulmonary Hypertension: Evolving Therapeutic Approaches for Operable and Inoperable Disease. J Am Coll Cardiol 2018;71:2468-86.

10. Ghofrani HA, D'Armini AM, Grimminger F, et al. Riociguat for the treatment of chronic thromboembolic pulmonary hypertension. $\mathrm{N}$ Engl J Med 2013;369:319-29.

11. Simonneau G, D'Armini AM, Ghofrani HA, et al. Riociguat for the treatment of chronic thromboembolic pulmonary hypertension: a long-term extension study
(CHEST-2). Eur Respir J 2015;45:1293-302.

12. Galie N, Humbert M, Vachiery JL, et al 2015 ESC/ ERS Guidelines for the diagnosis and treatment of pulmonary hypertension: The Joint Task Force for the Diagnosis and Treatment of Pulmonary Hypertension of the European Society of Cardiology (ESC) and the European Respiratory Society (ERS): Endorsed by: Association for European Paediatric and Congenital Cardiology (AEPC), International Society for Heart and Lung Transplantation (ISHLT). Eur Respir J 2015;46:903-75.

13. Pepke-Zaba J, Ghofrani HA, Hoeper MM. Medical management of chronic thromboembolic pulmonary hypertension. Eur Respir Rev 2017;26:160107.

14. Fukui S, Ogo T, Goto Y, et al. Exercise intolerance and ventilatory inefficiency improve early after balloon pulmonary angioplasty in patients with inoperable chronic thromboembolic pulmonary hypertension. Int J Cardiol 2015;180:66-8.

15. Mullin CJ, Klinger JR. Chronic Thromboembolic Pulmonary Hypertension. Heart Fail Clin 2018;14:339-51.

16. Nagel C, Prange F, Guth S, et al. Exercise training improves exercise capacity and quality of life in patients with inoperable or residual chronic thromboembolic pulmonary hypertension. PLoS One 2012;7:e41603.

17. Hoeper MM, Huscher D, Ghofrani HA, et al. Elderly patients diagnosed with idiopathic pulmonary arterial hypertension: results from the COMPERA registry. Int J Cardiol 2013;168:871-80.

18. Grunig E, Eichstaedt C, Barbera JA, et al. ERS statement on exercise training and rehabilitation in patients with severe chronic pulmonary hypertension. Eur Respir J 2019;53:1800332.

19. Fukui S, Ogo T, Takaki H, et al. Efficacy of cardiac rehabilitation after balloon pulmonary angioplasty for chronic thromboembolic pulmonary hypertension. Heart 2016;102:1403-9.

20. La Rovere MT, Pinna GD, Pin M, et al. Exercise Training After Pulmonary Endarterectomy for Patients with Chronic Thromboembolic Pulmonary Hypertension. Respiration 2019;97:234-41.

21. Nagel C, Nasereddin M, Benjamin N, et al. Supervised Exercise Training in Patients with Chronic Thromboembolic Pulmonary Hypertension as Early Follow-Up Treatment after Pulmonary Endarterectomy: A Prospective Cohort Study. 
Respiration 2020;99:577-88.

22. Inagaki $T$, Terada J, Tanabe N, et al. Home-based pulmonary rehabilitation in patients with inoperable or residual chronic thromboembolic pulmonary hypertension: a preliminary study. Respir Investig 2014;52:357-64.

23. Moher D, Liberati A, Tetzlaff J, et al. Preferred reporting items for systematic reviews and metaanalyses: the PRISMA statement. PLoS Med 2009;6:e1000097.

24. Galie N, Humbert M, Vachiery JL, et al 2015 ESC/ ERS Guidelines for the Diagnosis and Treatment of Pulmonary Hypertension. Rev Esp Cardiol (Engl Ed) 2016;69:177.

25. Ma LL, Wang YY, Yang ZH, et al. Methodological quality (risk of bias) assessment tools for primary and secondary medical studies: what are they and which is better? Mil Med Res 2020;7:7.

26. Cumpston M, Li T, Page MJ, et al. Updated guidance for trusted systematic reviews: a new edition of the Cochrane Handbook for Systematic Reviews of Interventions. Cochrane Database Syst Rev 2019;10:ED000142.

27. Grünig E, Lichtblau M, Ehlken N, et al. Safety and efficacy of exercise training in various forms of pulmonary hypertension. Eur Respir J 2012;40:84-92.

28. Mathai SC, Ghofrani HA, Mayer E, et al. Quality of life in patients with chronic thromboembolic pulmonary hypertension. Eur Respir J 2016;48:526-37.

29. Harzheim D, Klose H, Pinado FP, et al. Anxiety and depression disorders in patients with pulmonary arterial hypertension and chronic thromboembolic pulmonary hypertension. Respir Res 2013;14:104.

30. Galiè N, Corris PA, Frost A, et al. Updated treatment algorithm of pulmonary arterial hypertension. J Am Coll Cardiol 2013;62:D60-72.

31. Yuan P, Yuan XT, Sun XY, et al. Exercise training for pulmonary hypertension: a systematic review and metaanalysis. Int J Cardiol 2015;178:142-6.

32. Delcroix M, Lang I, Pepke-Zaba J, et al. Long-Term Outcome of Patients With Chronic Thromboembolic Pulmonary Hypertension: Results From an International Prospective Registry. Circulation 2016;133:859-71.

33. Ehlken N, Lichtblau M, Klose H, et al. Exercise training improves peak oxygen consumption and haemodynamics in patients with severe pulmonary arterial hypertension and inoperable chronic thrombo-embolic pulmonary hypertension: a prospective, randomized, controlled trial. Eur Heart J 2016;37:35-44.

34. Kataoka M, Inami T, et al. Balloon Pulmonary Angioplasty (Percutaneous Transluminal Pulmonary Angioplasty) for Chronic Thromboembolic Pulmonary Hypertension: A Japanese Perspective. JACC Cardiovasc Interv 2019;12:1382-8.

35. Ito R, Yamashita J, Sasaki Y, et al. Efficacy and safety of balloon pulmonary angioplasty for residual pulmonary hypertension after pulmonary endarterectomy. Int J Cardiol 2021;334:105-9.

36. Zhang L, Bai Y, Yan P, et al. Balloon pulmonary angioplasty vs. pulmonary endarterectomy in patients with chronic thromboembolic pulmonary hypertension: a systematic review and meta-analysis. Heart Fail Rev 2021;26:897-917.

37. Grunig E, Maier F, Ehlken N, et al. Exercise training in pulmonary arterial hypertension associated with connective tissue diseases. Arthritis Res Ther 2012;14:R148.

38. Weinstein AA, Chin LM, Keyser RE, et al. Effect of aerobic exercise training on fatigue and physical activity in patients with pulmonary arterial hypertension. Respir Med 2013;107:778-84.

39. Pandey A, Garg S, Khunger M, et al. Efficacy and Safety of Exercise Training in Chronic Pulmonary Hypertension: Systematic Review and Meta-Analysis. Circ Heart Fail 2015;8:1032-43.

40. Zhao YL, Yuan P, Zhao QH, et al. Comparative Effectiveness of Exercise Training for Patients With Chronic Thromboembolic Pulmonary Hypertension After Pulmonary Endarterectomy: A Systematic Review and Meta-Analysis. Front Cardiovasc Med 2021;8:664984.

41. Sun XG, Hansen JE, Oudiz RJ, et al. Exercise pathophysiology in patients with primary pulmonary hypertension. Circulation 2001;104:429-35.

42. Manders E, Rain S, Bogaard HJ, et al. The striated muscles in pulmonary arterial hypertension: adaptations beyond the right ventricle. Eur Respir J 2015;46:832-42.

43. de Man FS, Handoko ML, Groepenhoff H, et al. Effects of exercise training in patients with idiopathic pulmonary arterial hypertension. Eur Respir J 2009;34:669-75.

44. Tran D, Munoz P, Lau EMT, et al. Inspiratory Muscle Training Improves Inspiratory Muscle Strength 
and Functional Exercise Capacity in Pulmonary Arterial Hypertension and Chronic Thromboembolic Pulmonary Hypertension: A Pilot Randomised
Controlled Study. Heart Lung Circ 2021;30:388-95.

(English Language Editor: C. Betlzar)

Cite this article as: An QY, Wang L, Yuan P, Zhao QH, Gong SG, Zhang R, He J, Luo CJ, Qiu HL, Li HT, Liu JM, Wang JJ, Cheng K, Jiang R. Effectiveness and safety of exercise training and rehabilitation in chronic thromboembolic pulmonary hypertension: a systematic review and meta-analysis. Ann Palliat Med 2021;10(7):8134-8146. doi: 10.21037/apm-21-1758 


\section{Supplementary}

Table S1 The National Institutes of Health (NIH) quality assessment tool for before-after (pre-post) study with no control group

\begin{tabular}{|c|c|c|c|c|c|}
\hline Major Components & \multicolumn{5}{|c|}{ Response options } \\
\hline $\begin{array}{l}\text { 2. Were eligibility/selection criteria for the study population } \\
\text { prespecified and clearly described? }\end{array}$ & Yes & Yes & Yes & Yes & Yes \\
\hline $\begin{array}{l}\text { 4. Were all eligible participants that met the prespecified } \\
\text { entry criteria enrolled? }\end{array}$ & Yes & Yes & Yes & Yes & Yes \\
\hline $\begin{array}{l}\text { 5. Was the sample size sufficiently large to provide } \\
\text { confidence in the findings? }\end{array}$ & Yes & Yes & Yes & Yes & Yes \\
\hline $\begin{array}{l}\text { 7. Were the outcome measures prespecified, clearly defined, } \\
\text { valid, reliable, and assessed consistently across all study } \\
\text { participants? }\end{array}$ & Yes & Yes & Yes & Yes & Yes \\
\hline $\begin{array}{l}\text { 8. Were the people assessing the outcomes blinded to the } \\
\text { participants' exposures/interventions? }\end{array}$ & $\begin{array}{l}\text { Not } \\
\text { Applicable }\end{array}$ & $\begin{array}{l}\text { Not } \\
\text { Applicable }\end{array}$ & $\begin{array}{l}\text { Not } \\
\text { Applicable }\end{array}$ & $\begin{array}{l}\text { Not } \\
\text { Applicable }\end{array}$ & $\begin{array}{l}\text { Not } \\
\text { Applicable }\end{array}$ \\
\hline $\begin{array}{l}\text { 9. Was the loss to follow-up after baseline } 20 \% \text { or less? } \\
\text { Were those lost to follow-up accounted for in the analysis? }\end{array}$ & Yes & Yes & Yes & Yes & Yes \\
\hline $\begin{array}{l}\text { 10. Did the statistical methods examine changes in outcome } \\
\text { measures from before to after the intervention? Were } \\
\text { statistical tests done that provided p values for the } \\
\text { pre-to-post changes? }\end{array}$ & Yes & Yes & Yes & Yes & Yes \\
\hline $\begin{array}{l}\text { 12. If the intervention was conducted at a group level } \\
\text { (e.g., a whole hospital, a community, etc.) did the statistical } \\
\text { analysis take into account the use of individual-level data to } \\
\text { determine effects at the group level? }\end{array}$ & Not Reported & Not Reported & d Not Reported & Not Reported & Not Reported \\
\hline Quality Rating & Good & Good & Good & Good & Good \\
\hline
\end{tabular}

Source: National Heart, Lung, and Blood Institute; National Institutes of Health; U.S. Department of Health and Human Services. 